\title{
Efficiency of Passive Utilization of Ground "Cold" in Adaptive Geothermal Heat Pump Heating and Cooling Systems (AGHCS)
}

\author{
Vasilyev G.P. ${ }^{1}$, Gornov V.F. ${ }^{1}$, Kolesova M.V. ${ }^{1}$, Dmitriev A.N. ${ }^{2}$, Silaeva V.G. ${ }^{1}$ \\ 1 JSC «INSOLAR-INVEST», Bol'shaya Filevskaya str. 32-3, Moscow, 121433 Russia \\ ${ }^{2}$ Department of Economics and Managing the City Construction, Engineering and Economic Faculty of the Russian Plekhanov \\ Economic Academy, Moscow, Russia
}

\begin{abstract}
This article deals with estimating a potential and efficiency of utilization of passive ground "cold" for cooling buildings in climatic conditions of Moscow (Russia). The article presents results of numerical analysis to assess the efficiency of reducing peak cooling loads of the building equipped with AGHCS, through the utilization of natural cold of wells for passive cooling and cold storage in summer at night (off-peak) time with its subsequent consumption in the day time, both in passive mode, and with heat pumps. The conclusions of the article set out the basic principles of passive cooling in the design of AGHCS.
\end{abstract}

\section{Introduction}

Today, geothermal heat pump heating systems (GHCS) are already widely used in temperate regions of the world (North America, Europe, and China [1]). Extensive global experience of practical utilization of geothermal heat pump heating and cooling systems (GHCS) gained over the past decades identified the most urgent challenges for their mass implementation both abroad and in Russia.

The basic force constraining widespread application of GHCS are high initial capital investments in the system caused not only by high investments in construction of borehole heat exchangers (BHEs) directly ensuring low-grade geothermal heat recovery, but also by significant costs associated with increase in the electrical load of a building and by throughput capacity of electrical networks of a building. In recent years, due to global warming, even in the middle of Russia, summer load on the building cooling system is becoming increasingly important, and such load is often comparable and sometimes higher than winter heating load. As a result, in some cases, actual summer cooling load of a building determines the rated capacity of electric drive of heat pump heating and cooling systems. Moreover, costs associated with increase in the electrical load of a building and throughput capacity of electrical networks of a building are decisive when deciding on the application of GHCS.

At the same time, majority of Russian regions are characterized by low natural ground temperatures and long-lasting heating period, and therefore the long-term operation of GHCS in ground and climatic conditions of the most regions of the Russian Federation is almost always associated with freezing/defrosting the ground surrounding BHEs and storage of a great deal of cold in the ground, which should be utilized in summer for cooling a building. Research presented in this article is focused on addressing this challenge and estimating a potential and efficiency of utilization of passive ground "cold" for cooling buildings in geo-climatic conditions of Russia.

Distinction of these numerical experiments was the need to take into account the processes of freezing/defrosting of pore water in the ground surrounding BHEs when simulating processes accompanying AGHCS operation. Study of existing models of heat transfer processes in the "ground-BHE" system [2, 3] showed virtual absence of generally accepted algorithms for solving this problem and, in particular, consideration of phase transformations of pore water in the ground. In summary, numerical experiments have been carried out with the use of the software package "INSOLAR.GSHP.12" developed by the Russian company INSOLAR-INVEST. The software package "INSOLAR.GSHP.12" allows to simulate the thermal conditions of the ground mass of low-grade geothermal heat collection system in the long-term operation of AGHCS [4], taking into account phase transformations processes of pore water in the ground [5, $6]$.

\section{Baseline building}

The baseline building used during the numerical experiments was the real experimental building located at the address: Moscow, Bolshaya Filevskaya Street, estate 22, build. 2, equipped with a pilot AGHCS. Total 
building area is 278 sq. $\mathrm{m}$. The building has three floors. The experimental building has the shape and plan of volute. The basic technical characteristics of the baseline experimental building are shown in Table 1.

Table 1. Basic technical characteristics of the baseline experimental building

\begin{tabular}{|l|l|l|}
\hline \multicolumn{3}{|l|}{ Baseline experimental building area: $278 \mathrm{~m}^{2}$} \\
\hline $\begin{array}{l}\text { Building envelope } \\
\text { name }\end{array}$ & $\begin{array}{l}\text { Reduced heat-transfer } \\
\text { resistance } \mathrm{R}, \mathrm{m} 2 \mathrm{x}^{\circ} \mathrm{C} / \mathrm{W}\end{array}$ & $\begin{array}{l}\text { Area, } \\
\mathrm{m}^{2}\end{array}$ \\
\hline Exterior walls & 3,7 & 210 \\
\hline 1st floor coating & 4,5 & 122 \\
\hline Coating & 4 & 170 \\
\hline Windows & 0,8 & 36 \\
\hline Stained glass & 0,6 & 40 \\
\hline
\end{tabular}

Photo of the baseline experimental building is shown in Fig. 1, and its sectional view is shown in Fig. 2.

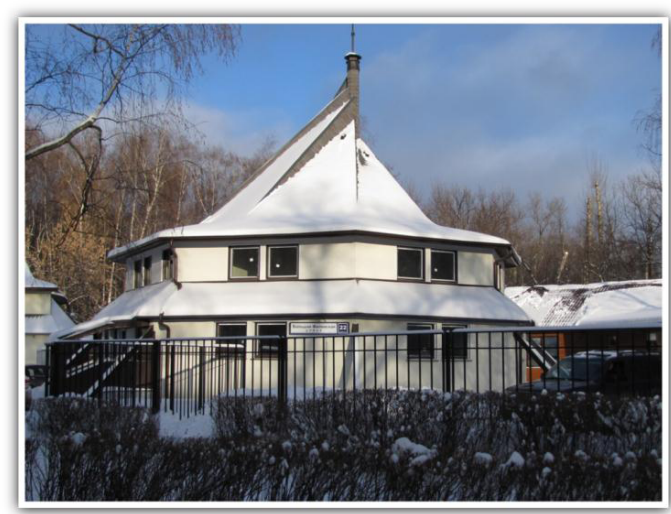

Figure 1. Photo of the baseline experimental building

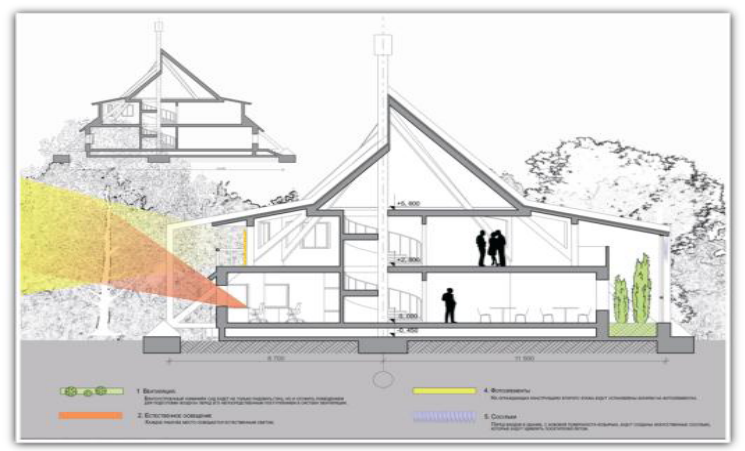

Figure 2. Sectional view of the baseline experimental building

\section{Numerical analysis}

Numerical analysis was carried out for the baseline building equipped with AGHCS, as described in section 1 . Building envelope and technical characteristics of the baseline building are shown in Table 1 and did not changed during numerical analysis. The only changes were modes of operation and, consequently, loads on engineering systems of buildings.

Numerical experiments were carried out for climatic conditions of Moscow. The calculated parameters of outside air were taken in accordance with SP 131.13330.2012 "SNIP 23-01-99* Building Climatology": Summer period - design outside dry bulb temperature is $+26,3^{\circ} \mathrm{C}$, enthalpy is $56.8 \mathrm{~kJ} / \mathrm{kg}$ (relative humidity $56 \%$ ).
As a typical climate year, 2013 year was selected as the most close to year with figures, averaged over the past 30 years.

In conducting numerical analysis, models of the baseline building AGHCS were considered in a variety of configurations using natural cold of BHEs for passive cooling and cold storage in the summer period at night (off-peak) time with its subsequent consumption in the day time both in the passive mode, and with heat pumps.

\subsection{Numerical experiment 1. GHCS of the baseline building using heat pumps in summer in the reverse mode with air-cooled condenser and heat release into the atmosphere}

Numerical analysis 1 is actually a basic version of AGHCS configuration, which efficiency was compared with various AGHCS configurations using natural cold of BHEs for passive cooling and cold storage.

In order to cover the building cooling loads in summer (June-August), this analysis did not account a ground. Capacity of the installed electrical equipment was determined as the sum of electric capacities of heat pumps + peak power cinch + circulating pumps, fans, etc. Domestic hot water supply was not available.

Fig. 3 shows charts of coolant temperature variation at the inlet (coldest point) of the low-grade geothermal heat collection system for 1,3 and 5 years of AGHCS operation, and Fig. 4 shows resizing of ice lens frozen around BHE.

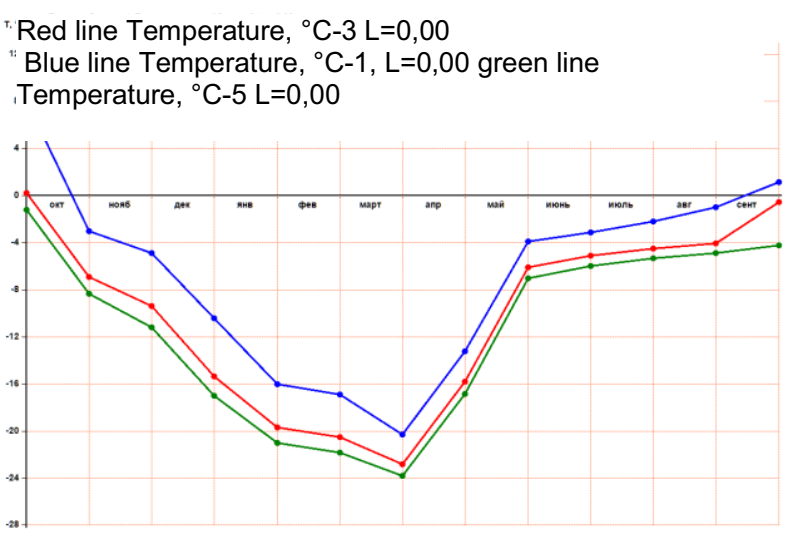

Figure 3. Variation of temperature of coolant of the ground low-grade heat collection system for 1,3 and 5 years of GHCS

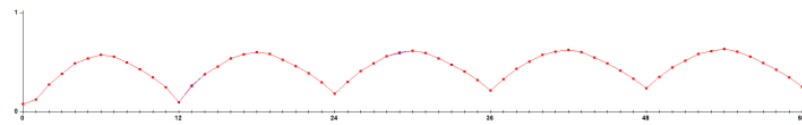

Figure 4. Resizing of ice lens frozen around BHE (X-axis time in months, Y-axis - ice lens radius, $\mathrm{m}$ )

Analysis of charts and graphs shown in Figs. 1 and 2 shows that in this AGHCS configuration the coolant and thus the ground temperature decreases with each year of operation and by the end of March of the 5th year of operation, the minimum coolant temperature in the ground heat collecting system reaches $-24{ }^{\circ} \mathrm{C}$. This situation, in turn, leads to grow of ice lenses around BHE which are decreased in size in summer, but not defrosted completely and by the end of March of the 5th year of 
operation reach 1,-1.2 $\mathrm{m}$ diameter. This situation results to relatively low AGHCS coefficients of performance (COP) for the 5th year of operation, which values are shown in Fig. 5. It is obvious that the "cold" stored in ice lenses, can be effectively used in summer for passive cooling.

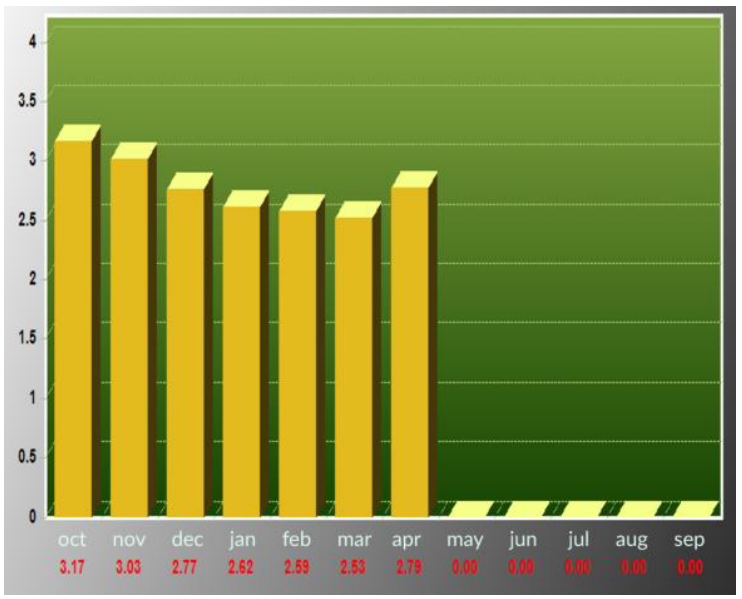

Figure 5. GHCS coefficients of performance by the 5 th year of operation

Table 2 shows results of Analysis 1. During the summer period, the building cooling is ensured by heat pumps, ground cooling capacity is not used.

Table 2. Results of analysis 1

\begin{tabular}{|l|l|}
\hline $\begin{array}{l}\text { Capacity of the installed electrical equipment } \\
\text { (HPS + peak power cinches + circulating } \\
\text { pumps), Wyst }\end{array}$ & $5.86 \mathrm{~kW}$ \\
\hline $\begin{array}{l}\text { Electric energy consumption (for the 5th year of } \\
\text { operation) for GHCS (heating), Ws }\end{array}$ & $\begin{array}{l}17397.15 \\
\mathrm{~kW} \cdot \mathrm{h}\end{array}$ \\
\hline $\begin{array}{l}\text { Electric energy consumption (for the 5th year of } \\
\text { operation) for GHCS (cooling), } \mathrm{W}_{\text {hol }}\end{array}$ & $\begin{array}{l}1117 \\
\mathrm{~kW} \cdot \mathrm{h}\end{array}$ \\
\hline
\end{tabular}

\subsection{Numerical experiment 2. GHCS of the baseline building with passive utilization of "cold" stored in BHEs in winter for building cooling in summer}

The numerical experiment 2 studied efficiency of passive utilization of "cold" stored in BHEs in winter for building cooling in summer. In order to cover the building cooling loads in summer (June-August), this experiment accounted a ground contribution. Capacity of the installed electrical equipment was determined as the sum of electric capacities of heat pumps + peak power cinch + circulating pumps, fans, etc. Domestic hot water supply was not available.

Fig. 6 shows charts of coolant temperature variation at the inlet (coldest point) of the ground low-grade heat collection system for 1,3 and 5 years of AGHCS operation, and Fig. 6 shows resizing of ice lense frozen around BHE.

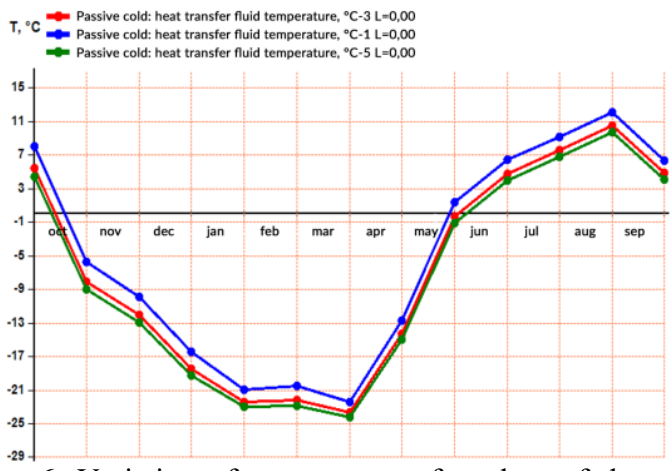

Figure 6. Variation of temperature of coolant of the ground low-grade heat collection system for 1,3 and 5 years of AGHCS

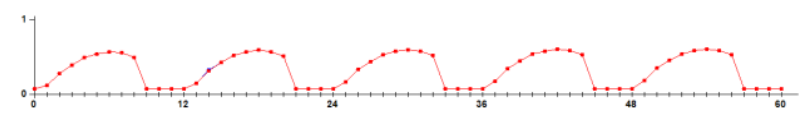

Figure 7. Resizing of ice lens frozen around BHE (X-axis time in months, Y-axis - ice lens radius)

Analysis of charts shows that in this analysis, the ground substantially recovers its temperature potential by the beginning of each new heating season, and even reaches the zone of positive temperatures by the beginning of the 6th heating season. Consumption of "cold" from the ground and related heat energy "release" into the ground, in turn, lead to a complete defrosting of ice lenses grown around BHEs in winter. This situation results to increased (in comparison with analysis 1) AGHCS coefficients of performance (COP) for the 5th year of operation, which values are shown in Fig. 8.

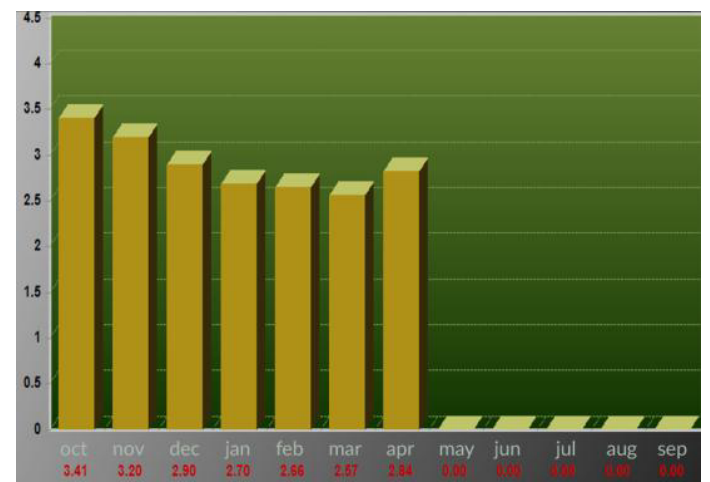

Figure 8. AGHCS coefficients of performance (COP) by the 5 th year of operation

Table 3 shows the main results of Experiment 2 . During the summer period, building cooling is provided from ground without heat pumps - only circulation pumps of the low-grade heat collection system and the building cooling system operate during this period.

Table 3. Main results of experiment 2

\begin{tabular}{|l|l|}
\hline $\begin{array}{l}\text { Design capacity of the installed electrical } \\
\text { equipment (HPS + peak power cinches }+ \\
\text { circulating pumps), Wyst }\end{array}$ & $5.86 \mathrm{~kW}$ \\
\hline $\begin{array}{l}\text { Electric energy consumption (for the } 5 \text { th year of } \\
\text { operation) for GHCS (heating), Ws }\end{array}$ & $\begin{array}{l}17009.25 \\
\mathrm{~kW} \cdot \mathrm{h}\end{array}$ \\
\hline $\begin{array}{l}\text { Electric energy consumption (for the } 5 \text { th year of } \\
\text { operation) for GHCS (cooling), } \mathrm{W}_{\text {hol }}\end{array}$ & $215 \mathrm{~kW} \cdot \mathrm{h}$ \\
\hline
\end{tabular}


3.3 Numerical experiment 3. GHCS of the baseline building using natural cold of BHEs for passive cooling and cold storage in the summer period at night (off-peak) time with its subsequent consumption in the day time both in the passive mode, and with heat pumps

The numerical experiment 3 studied efficiency of utilization of natural cold of BHEs for passive cooling and cold storage in the summer period at night (off-peak) time with its subsequent consumption in the day time both in the passive mode, and with heat pumps. Capacity of the installed electrical equipment was determined as the sum of electric capacities of heat pumps + peak power cinch + circulating pumps, fans, etc. Domestic hot water supply was not available. The experiment considered the temperature mode of coolant of the low-grade geothermal heat collection system in the warmest months of the year, from May to July. Variation of outside air temperature in May of the typical climate year is shown in Fig. 9.

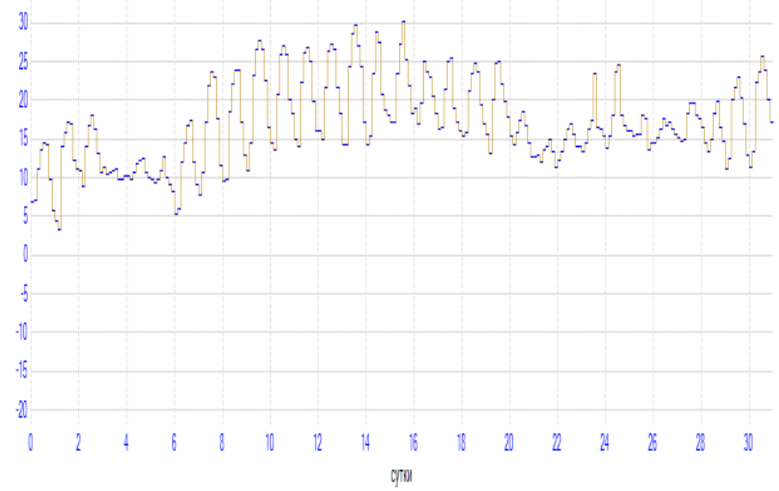

Figure 9. Outside air temperature in May

Fig. 10-Fig. 12 show variation of the coolant temperature at the inlet/outlet of the ground low-grade geothermal heat collection system in May and June when using natural ground cold for passive cooling of the building. In this case, heat pumps did not run and building cooling was fully ensured by the natural ground cold.

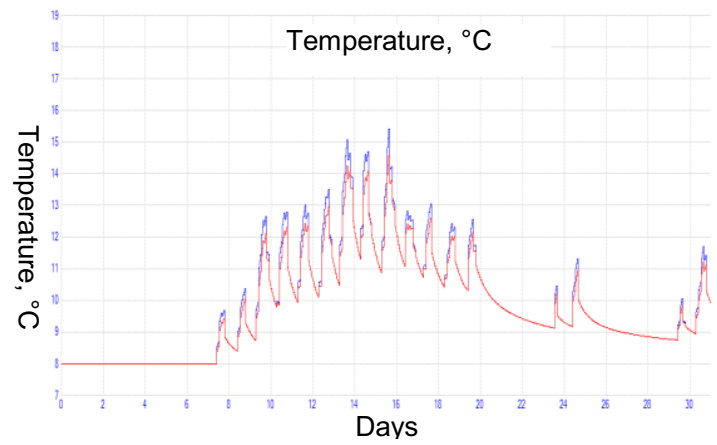

Figure 10. Coolant temperature at the inlet/outlet of the lowgrade geothermal heat collection system in May when passive cooling by natural ground cold without heat pumps

Analysis of these charts shows that in the climatic conditions of the Moscow region, cooling of the baseline building can be fully achieved through the natural ground cold. As it can be seen from Figure 10, even in the warmest day, the collection system coolant temperature does not rise above $17^{\circ} \mathrm{C}$ that is sufficient to provide the building air-conditioning system with cold.

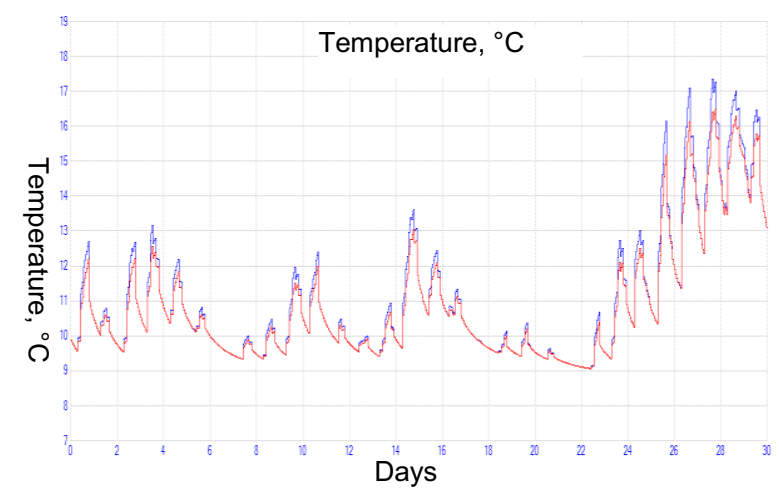

Figure 11. Coolant temperature at the inlet/outlet of the lowgrade geothermal heat collection system in June when passive cooling by natural ground cold without heat pumps

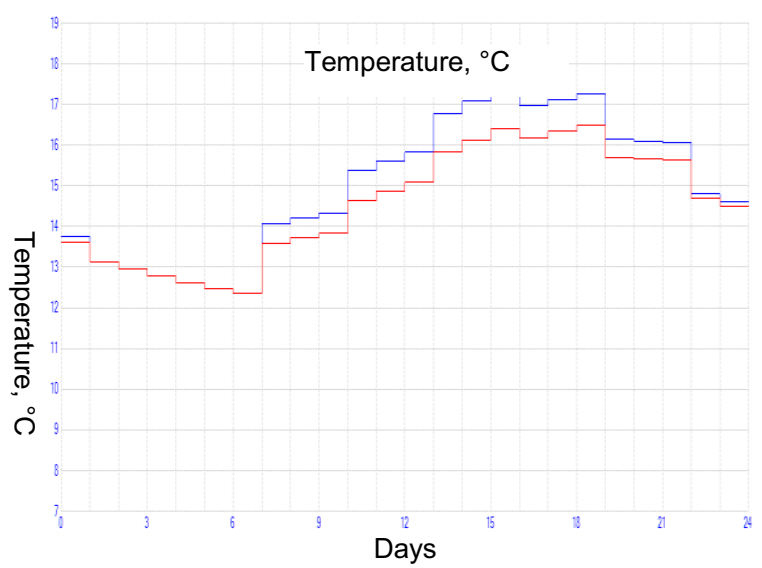

Figure 12. Coolant temperature at the inlet/outlet of the ground low-grade geothermal heat collection system in the warmest day of the year (June 28) when passive cooling by natural ground cold without heat pumps

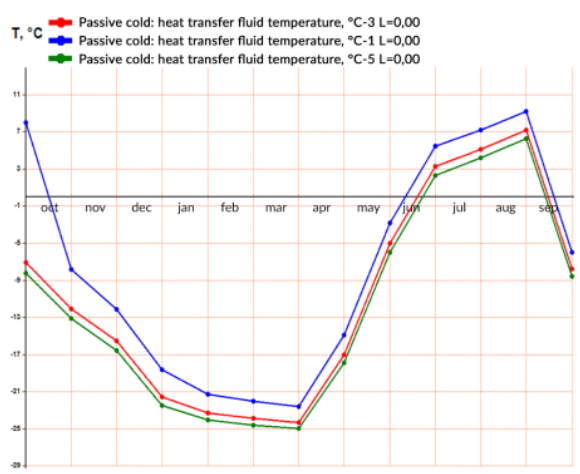

Figure 13. Coolant temperature at the inlet of the low-grade geothermal heat collection system by 1,3 and 5 years of operation when passive cooling with the use of heat pumps

Fig. 13-Fig. 16 show charts of the heat collection system coolant temperature variations with passive use of cold stored in the ground and with the use of heat pumps.

As we can see from these charts, this modification very effectively uses "cold", generated by heat pumps in winter and stored in the ground. As it can be seen from Fig. 15 and Fig. 16, temperature of the coolant supplied 
to the building air conditioning system, does not exceed $12^{\circ} \mathrm{C}$ even in the warmest time of the year. A very important factor is the fact that, as it can be seen from charts, load release to the air conditioning system at night results to "cold charging" of the heat collection system. The cold is supplied, or "pumped", from the layers of ground surrounding BHE. This effect is clearly expressed in the charts. If necessary, this effect can be enhanced by powering heat pumps at night and fast "cold recharging" of the heat collection system.

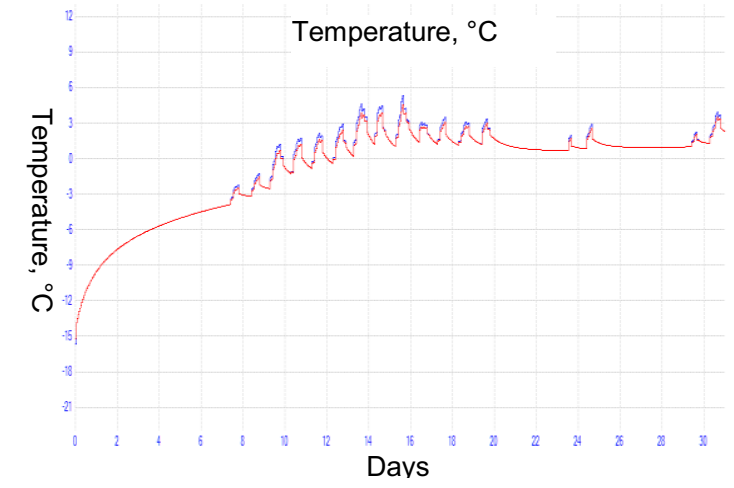

Figure 14. Coolant temperature at the inlet/outlet of the lowgrade geothermal heat collection system in May when passive cooling with the use of heat pumps

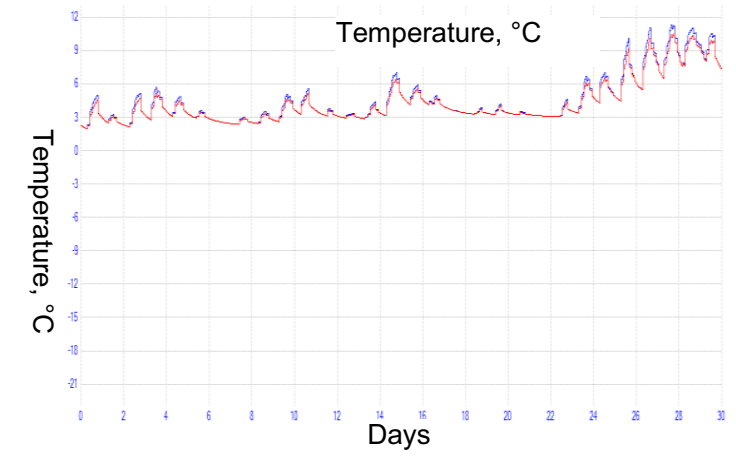

Figure 15. Coolant temperature at the inlet/outlet of the lowgrade geothermal heat collection system in June when passive cooling with the use of heat pumps

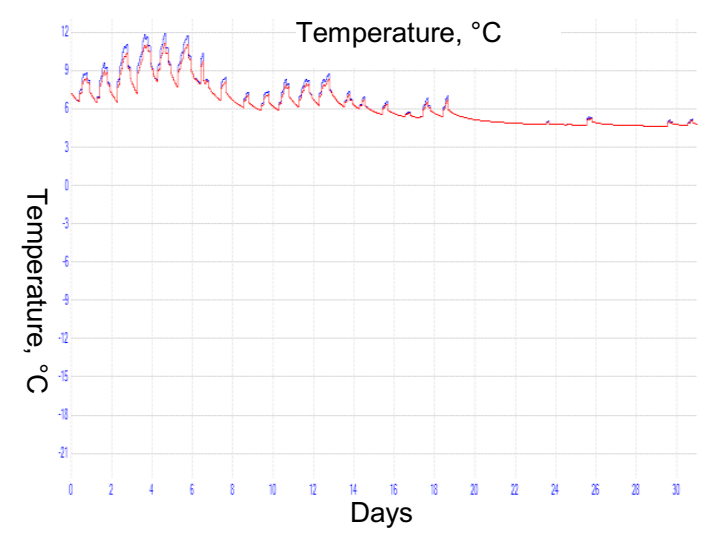

Figure 16. Coolant temperature at the inlet/outlet of the lowgrade geothermal heat collection system in July when passive cooling with the use of heat pumps

\section{Conclusion}

Research presented in this article allowed to formulate the following principles for passive utilization of ground "cold" in the design of AGHCS.

1. When designing AGHCS, it is necessary to make the best use of passive cooling by cold stored in the ground in winter that not only allows for the building cooling without powering the heat pumps, but also significantly increases its (building) energy efficiency and energy savings by about $7 \%$.

2. When using the cold stored in the ground of the heat collection system in summer, it is necessary to seek to its passive utilization in the air conditioning system of the building without heat pumps, while in case of lack of the ground cooling capacity heat pumps could be powered in the night time (with offpeak electricity rates) for "cold charging" of the heat collection system.

3. Use of cold stored in the ground of the heat collection system for direct cooling heat pump condensers during the summer period is impractical.

4. When designing GHCS, it is necessary to take into account the effect of "cold addition" from the ground layers surrounding BHE observed in the night time when load release to the air conditioning system. If necessary, this effect can be enhanced by powering heat pumps at night and fast "cold recharging" of the heat collection system.

\section{Acknowledgements}

The research was conducted by JSC "INSOLARINVEST" with the financial support of the Ministry of Education and Science of Russia. Unique identifier of the project RFMEFI57914X0026.

\section{References}

1. Lund J.W., Freeston D.H., Boyd T.L. Direct utilization of geothermal energy 2010 worldwide review. Geothermics, 40, (2011) 159-180.

2. Yang H., Cui P., Fang Z. Vertical-borehole groundcoupled heat pumps: A review of models and systems, Applied Energy, 87, (2010) 16-27.

3. Lamarche L., Kajl S., Beauchamp B. A review of methods to evaluate borehole thermal resistances in geothermal heat-pump systems. Geothermics, 39 (2010) 187-200.

4. G.P. Vasilyev, N.V. Peskov, M.M. Brodach, V.A. Lichman, A.N. Dmitriev, V.F. Gornov, M.V. Kolesova, "Estimation of the thermal effect of ground moisture condensation on heat transfer outside a geothermal borehole", Energy and Buildings, 82 (2014) 795-798.

5. G. P. Vasilyev, N. V. Peskov, V. A. Lichman, V. F. Gornov, M. V. Kolesova, "Simulating the thermal operating conditions in the thermal wells of ground source heat pump heat supply systems," Part I: Accounting the Porous Moisture Freezing Processes 
in Soil, Thermal Engineering, 62(8), (2015) pp. 547552.

6. Carslaw H.S., Jaeger J.C. Conduction of heat in solids. Oxford UK: Claremore Press, (1946).
7. Ingersoll L.R., Zobel O.J., Ingersoll A.C. Heat conduction with engineering, geological, and other applications. New York: McGraw-Hill, (1954). 